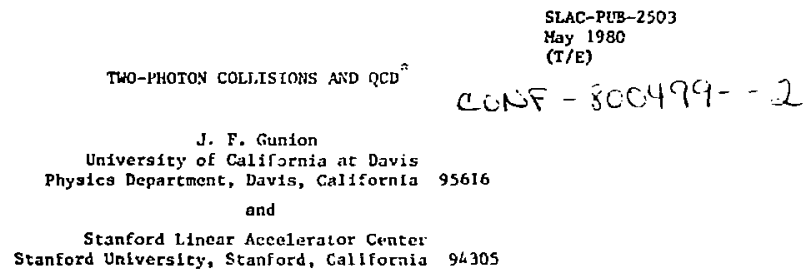

\title{
Abstract.
}

A critical revieu of the applications of QCD to loh- and $h$ f $g h-P_{T}$ interactions of two photons 15 presented. The advantages of the two-photon high-p tests over corresponding hadronic beam and/or target tests of QCD are given particular emphasis.

Regults for the tho-photon Interactions are wow beconlug avallable from expertments at PETRA and two-photon experiments at PEP will soon begln. Thus, it seems an opportune time to review and assess the implications of current theorctical ideas, especially of quantum chromodynamics, far photon-photon collisions. Particular etophasis 111 be placed upon the unique characteristlcs of I photan carget, photon beam combination as compared to the hadron carget situation. A brfef outline of the talk is:

I) Renarks on low- $p_{T}$ physics in $Y$ collistons.

11) Review of the saltent features of high-P hodron carget coilisions -problens and amblguities.

III) High-p $2 \gamma$ physics.

1. Inclusive fec and single farticle production

(a) 2-jet topology.

(b) 3-jet topology.

(c) 4-jet topology.

(d) Higher twist and vector dominance bockgrounds, and the Importance of single particle spectro.

2. Exclusive reactions.

Iv) Conclusions.

I have attempted to keep the number of equations minfmil and emphasize physical eeste and conclusions. This taik does not cover the deep Inclastis photon target Bltuatinn, reviewed by $T$. Walsh at this conferance.

* Work supported in picc by the Departake of Finergy unjer sentract DE-ACO3-765Fo051j and the $A, P$. Sloan Fuundatinn.

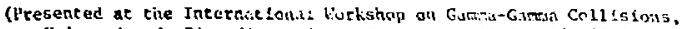
Universile de Picerdle, Mtans, France, ipril $3-12,19 \mathrm{bo}$ )

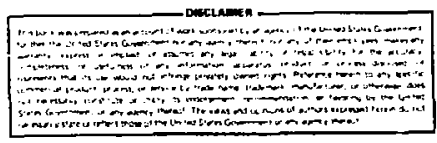




\section{Lot-p $\mathrm{T}$ Physics in $2 y$ Collialone}

The fundamental observable In $2 \mathrm{r}$ colligions at low- $\mathrm{P}_{\mathrm{T}}$ is the total cross aection,

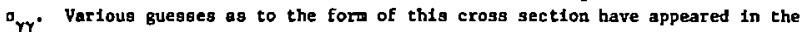
literature over the years. I I w11l present a polnt of view which differs silghtly fron those given earlier.

Most workers agree that ory cannot be obtained entirely from vector dominance. The photons have additional point-1ike couplings whlch presumably yleld an oddition to $\sigma_{Y y}$ bove the yector dominance estjnate. These point-like couplings can, In particular, lead to fixed-pole $(\mathrm{J}=0)$ contributions to the large $s$ limit of $\mathrm{or}^{*} A$ typical vector doninance estiazte of $\sigma_{Y Y}$ would include only the diagrams of Fig. 1. There ve enploy the Low-tiussinov ${ }^{2}$ gluon exciange model for the Pomeron and represent Regge exchanges ag due to quark exchange (as in the dualtty aproach) with all possible gluon radiative corrections.

The point-11ke coupling diagrams of FIg. 2 are not Included in the VW diagrans of $\mathrm{FI}_{\mathrm{B}}$. 1. Of course, interference terms between yecto-dominated ( $V$ ) type couplings and polnt-1ike (PL) couplings are also possible. An estimate for the Pomezon contribution to $\sigma_{Y \gamma}$, whlch includes both $V$ and PL couplings can be obtained from factorization,

$$
\lim _{a \rightarrow-} \sigma_{Y Y}=\lim _{a \rightarrow \infty} \frac{\sigma_{Y P}^{2}}{\sigma_{P P}} \sim 240 \mathrm{nb}
$$

aince the Pomeron contribution to the YP crose section should contain both $V$ and $P L$ $\gamma$ couplings. Certainly In the gluon-exchange Pomeron model the above result is explicitly correct. As estionat: for the Regge contribution ${ }^{1}$ from Vid is

$$
\sigma_{W}^{\text {Non-Poweron }} \sim \frac{270 \mathrm{nb}}{\sqrt{s\left(\mathrm{GeV}^{2}\right)}}
$$

Experientally it ia cleat that euch a Regge contribution is too small to describe the data ${ }^{3}$ wich preferg a fit with

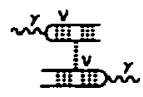

(a)

F18. 1. Vector dominance diagrans for ory: (a) Poneron or gluon exchange; and (b) Regge exchange, represented by radiatively nodifies quark exchange.

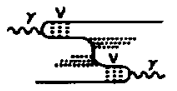

(b)

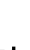




$$
\sigma_{r}^{\text {Mon-Poneron }} \sim \frac{840 \mathrm{nb}}{\sqrt{\mathrm{g}\left(\mathrm{GeV}^{2}\right)}}
$$

or else a smaller Regge tern whth some $J=0$ f 1 xed-pole contribution

$$
\sigma_{Y r}^{\text {Kon-Poperon }}-\frac{A}{\sqrt{8}}+\frac{B}{B}
$$

Theoret 1ca11y

$$
\sigma_{r}^{\text {Kon-Pomeron }}=\sigma_{W}^{\text {Non-Pomeron }}+2 \sigma_{V \text { PL }}^{\text {Norl-Poperon }}+\sigma_{\mathrm{PL} \mathrm{PL}}^{\text {Non-Pomeron }}
$$

Hil clearly be larger than the vector-dominance estimate, but cannot be explicitly calculated. It has, however, been suggegted that estimates using finite energy sum rules and duality may be possible. One such schere ${ }^{1}$ is to aake the fixed-pole plus vector-dominated Regge contributions

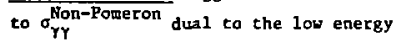
resonances; this implicticly assures that the polot-1ike photon components couple to rebonances but not to Regge
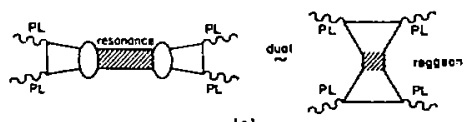

10]

terms. It seems nore reasonable to me that the point-11ke photon resonance component is dual co a point-iike Regge component. This is 1llustrated in F1g. 3(a). Corresponding stateenta apply to mixed vector-dominated and point-11ke couplingo; an exarole Is given in FIg. 3(b). Thus one would maintain a standard form for the finite energy sum rule
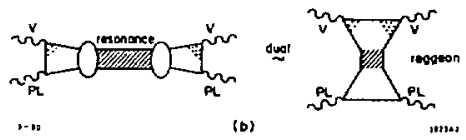

FIg. 3. Duality for $\sigma_{Y Y}-$ each $Y Y \rightarrow^{-}$ Resonance $\rightarrow$ ry diagram has its corresponding Reggeon diagram: (a) for all point-like (PL) couplings; and (b) for a sample alxed PL, vector-dominated (V) coupling diagram.

$$
\int_{a}^{1} \sigma_{Y Y}^{\text {Resonance }} \frac{d s}{s}-\int_{E_{0}}^{s_{1}} \sigma_{Y r}^{\text {Regge }} \frac{d s}{s}
$$

and the fact that the experinentally deterwined left-hand, resonance side of (1.6) Ia larger than the contribution to the right-hand side coring Eron pure vector

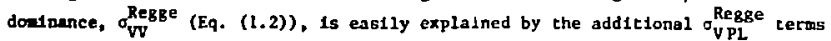
of (1.5) wich should be Included in (1.6). The Regge fit, (1.3), is wuch that (1.6) Is approxiastely satisfled, Ideally one would like to calculate the lefthand side of (1.6) with high preciaton (perhaps posstble as more resonance data becones avallable), deccmine ${ }_{Y Y}^{\text {Regge }}$ from (1.6) (1.e., deceraine $A$ in Eq. (1.4)) and then use the experinental messurement of $0_{Y Y}^{\text {Non-Poneron }}$ in decide if a fixcd-pole 
contribution (B/B in Eq. (1.4)) is present. Certainly one canot rule out a small fixed-pole term at the moment. Hovever, there seems to be no obvious justification for identifying the coeffictent, $B$, of the fixed-pole $1 / \mathrm{s}$ behavior with the coefficlent of $1 / \mathrm{s}$ obtained from the simple bare-fermion-loop box diagram. One must consider simultaneously all diagrams with gluon and/or fetmion bubble corrections to the bare fecmion loop. The $s+\infty$ inte of the sum of all such diagrams should then be separated Into Regge and fixed-pole terms; this calculation is not possible wthout first essentially solving the confinewent problen.

An interesting question is whether there 18 any direct way of exposing the point-11ke component of the photon using low $p_{T}$ observations. In fact most workers 4,5 who have examined the fragmentation $Y \rightarrow$ fast meson, $M$ agree that a point-ilike photon component will result in a softer-than-expected spectrum at high $x_{E}\left(x_{F}=\left(E_{M}+P_{M}^{z}\right) /\right.$ $\left.\left(E_{\mathbf{Y}}+\mathrm{P}_{\mathrm{M}}^{\mathrm{z}}\right)_{\max }\right)$ :

$$
\begin{aligned}
& \frac{d N}{d x_{F}} \sim\left(1-x_{F}\right)^{0} \\
& \frac{d N}{d x_{F}} \sim\left(1-x_{F}\right)^{1}
\end{aligned}
$$

point-1ike photon

$A$ sample model ${ }^{4}$ is that based on the QCD bremstrahlung diagrams of Fig. 4, which lllustrate $r \rightarrow$ meson fragmentation at low $\mathrm{P}_{\mathrm{T}}$. Basically, the meson remembers the fractional momentus diatribution of quarks in the photon. 5 For a vector-dowsnazed photon?

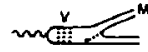

(.) (c)

P1g. 4. Bremstrahlung diagrans for $Y$ - neson, $M$ : (a) for the vector-doninated photon; and (b) for the point-11ke photon.

$$
G_{q / Y_{y}}(x) \sim(1-x)^{I}
$$

Whereas for point-1 ike photon

$$
G_{q / Y_{P L}}(x)-(1-x)^{0}
$$

The weaker suppression predicted for a point-like photon is epparently present ${ }^{9}$ in $Y P+$ fagt meson, $M$, where $M \cdot \pi^{+}$or - Is observed in the photon fragtentation region. The vame photon fragmentation spectrum should be observed in $\gamma$ y collisions.

In sunary, even at low $P_{T}$, we already have and can expect to find additional evidence in YY collisions for a non-vector-dominated component of the photon. Such evidence is, however, less ditect than that which can be obtained from rr collisions at high transverse morrentum. 


\section{Broblems and Amblguitles in H1gh-P $\mathrm{P}_{\mathrm{T}}$ Hadron Colligions}

First let us recall the sallent features of high-p $\mathrm{p}_{\mathrm{T}}$ collisions. The typlcal structure of a high-p $\mathrm{p}_{\mathrm{T}}$ inclusive jet cross section is illustrated in Fig. $j$. It has been proven ${ }^{10}$ that, In leading $l o g$, the correct procedure is to compute the jet cross section by convolutiog $\mathrm{P}_{\mathrm{T}}^{2}$ dependent distribution functions for the secondarles, a and b coming from $A$ and $B$ respectively, wich participate directly in the hard scatcering subprosesg $a+b \rightarrow c+d$, wth the cross section for that ubprocess: elther $c$ or $d$ can form the observed jet. Thus one has for $c=$ fet

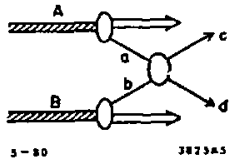

F1g. 5. $\mathrm{H} 1_{\mathrm{gh}}-\mathrm{p}_{\mathrm{T}}$ fet product1on.

$$
E_{c} \frac{d \sigma}{d^{3} P_{c}}=\frac{1}{\pi} \int d x_{a} d x_{b} G_{a / A}\left(x_{a}, P_{T}^{2}\right) G_{b / B}\left(x_{b}, P_{T}^{2}\right) \frac{d \sigma^{a+b}+c+d}{d t^{\prime}} s^{\prime} \delta\left(s^{\prime}+t^{\prime}+u^{\prime}\right)
$$

where $s^{\prime}=x_{a} x_{b} g_{v} s^{\prime}=x_{a} t, u^{\prime}=x_{b} u_{,} P_{T}^{2}=\frac{u^{\prime} t^{\prime}}{a^{\prime}}=\frac{u t}{s}$, and $s, t$ and $u$ are the Mandlestam lavariants appropriate to $A+B+c+x$. The distribution functions have the otandard scale-breaking behavior and can presumably be neasured via deep inelastic and/or asalve $\mu$-pair production.

The subprocess cross sections $\frac{d \sigma^{a+b}+c t d}{d t^{r}}$ are couputable in the approptiate large $6^{\prime}$, fixed sngle 1 imit in $Q W D$ even when some of the participating particles are non-elemencary. 11 The general form of the resul. is, ${ }^{+}$up to possible anomalouk dinension powers of $\log p_{T}^{2} / \Lambda^{2}$,

$$
\left.\frac{d a^{++b+c t d}}{d t^{\prime}}\right|_{\substack{\text { EIxed } \\ \text { angle }}} \sim \frac{1}{a^{n-2}}\left[a_{s}\left(p_{T}^{2}\right)\right]^{N-2} F_{a b c d}\left(\theta_{c . a *^{\prime}}^{\prime}\right)
$$

where 1a (2.1) s' $1 \mathrm{~s}$ of order $4 \mathrm{P}_{T}^{2}$ and $N=n_{a}+n_{b}+n_{c}+n_{d} 18$ the total number of elementary constluents particfpating in the subprocess. The atrong coupling constant ne the otandard form

$$
a_{0}\left(p_{T}^{2}\right)=\frac{4 \pi}{\left(11-\frac{2}{3} n_{f}\right) \log p_{T}^{2} / s^{2}}
$$

Scaling lawe of chls type are directly testable in exclusive scattering. For Inetance, Ignoring the as variaciod, one predicts and observes

+ Here we use a sonewhat simplifled expression, In actualley a glven ọcb diagram has $a_{a}{ }^{\prime}$ e evaluated at vartoug fractions of $P_{T}^{2}$ (a given Incernal gluon typically transfers only part of the overall momentum transfer). Serictly speaking, though, such corrections are part of the next-to-leading log correction to the leading log result $(2,2)$.

$$
-5-
$$




$$
\left.\frac{d \sigma}{d t}\right|_{\substack{\text { f1xed } \\
\text { angle }}} s \rightarrow \infty\left\{\begin{array}{l}
\frac{1}{\theta^{10}} ; p p+p p \\
\frac{1}{s^{8}} ; p+\tau p \\
\frac{1}{s^{7}} ; r p+r p \\
\frac{1}{s^{6}} ; Y p+r p
\end{array}\right.
$$

In addition, the constituent 1nterchange 2 (CIM) class of QCD diagrams (exampleo appear In FIg. 6) describe the angular dependence and crossing properties of such exclusive reactions extrenely we11. The normalizations in most cases have not been computed from first pinciples yet because of the large number of contributing graphe but the simpler diagrams for the plon and proton form factors have been computed and normalized. As an example consider $G_{M}^{\text {Proton }}\left(Q^{2}\right)$. One obtains ${ }^{13}$

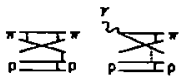

(a)

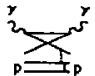

(c)

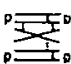

(d)

F1g. 6. Examp1ea of CIM type QCD diagrans for: (a) $\pi P+\pi P$; (b) $Y P+\pi P$; (c) $Y P+Y P$; and (d) $P P+P P$.

$$
q_{M}^{\text {proton }}\left(Q^{2}\right) \sim \frac{32 \pi^{2}}{9 Q^{4}} a_{a}^{2}\left(Q^{2}\right) \sum_{n, m=0}^{\infty} b_{n, m}\left[\log Q^{2} / \Lambda^{2}\right]^{-\gamma_{n}-\gamma_{m}}
$$

where the $b_{n}$ are computable given certain proton wave function information and $Y_{n}$ 1s the standard anomalous dimension appearing in deep inelastic scacrering. This expression agrees very vell with data provided $A^{2}<.01 \mathrm{GeV}^{2}$ (i.e., well belor the "standard" $\Lambda^{2}-.25 \mathrm{GeV}^{2}$ volue). This is 11lustrated in Fig. 7, taken from Ref. 11 , Focusing for a moment on the reactions involving photons $1 \mathrm{n}$ (2.4), it should be renarked that the experimentally observed decrease in the inverse $s$ power from $1 / s^{8}$ to $1 / \mathrm{s}^{7}$ and $1 / \mathrm{s}^{6}$ as one proceeds from a reaction involving no photons to ones with one and two photoni respectively is direct evidence for the point-ilka photon component. If the photon were purely vector-dominated $\pi p+\pi p, r p+\pi p$ and $r p+Y p$ thould all have the same fixed-angle a-dependence. Of course, the observed simple pover laus should, thearetically, be modified by appropriate powers of $a_{s}\left(p_{T}^{2}\right)$, unless a. Is slowly varying a when $\hbar$ is small. The requirement of small $A$ becones even wore crucial for the $1 / \mathrm{a}^{10}$ prediction for PP $\rightarrow$ pp which agrees well with data but $1 s$ accompanied by cen poser: of $a_{5}\left(\mathrm{P}_{T}^{2}\right)$. Unless $A$ is very small the extra variation with $p_{\mathrm{T}}^{2}$ incroduced in chls way descrays this sgreenent.

While predictions for exclusive reactions in QCD appear to be succesaful, Ignoring worries about the $a 1$ ize of $A$ ag reflected in the vartation of $a_{f}$. It is 
clear that 1nclusive reactions have the potential for probling more directly the most elementary QCD reactions such as $q q+q q$, $9 g+q g$, etc. which with $N=4$ gield, naively, $1 / \mathrm{p}_{\mathrm{T}}^{4}$ behavior in 1nclusive high $\mathrm{P}_{\mathrm{T}}$ scattering ( $3^{\prime}$ in (2.2) converta roughly to $4 p_{T}^{2}$ in the Inclustve cross section (2.1)). Unforturately, while the subprocesses important in Inclusive reactions are simpler the theoretical ambiguties are nore numeroug. In comparing theory to experiment in the inclusive altuation the following problems arlse.

(1) The question of the exact subprocers cross section behavior, 1.e., the uncertaid aize of $\Lambda$. This is the exact analogue of the exclusive reaction uncertainty.

(2) Correctione fron next-to-leading$\log$ terms, not incorporated in the leading order result $((2.1)+(2.2))$. These correc-

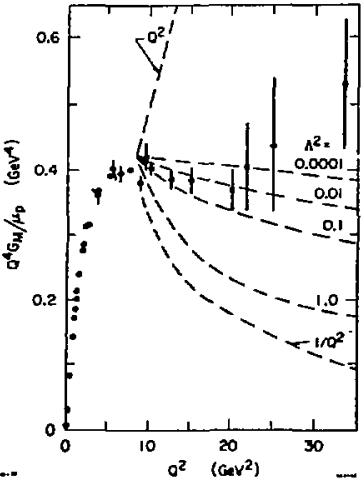

Fig. 7. Prediction for $Q^{4} C_{H}^{0}\left(Q^{2}\right)$ for varfous QCD ocale parameters $\lambda^{2}$ (In $\mathrm{Ger}^{2}$ ).

tione are in part to the distribution functions in (2.1) and in part to the subprocess cross sections (2.2). The combined next arder correction to inclusive fet production vis the subprocess qq $\rightarrow$ q has been found to be of order $50 \%-100 \%$. ${ }^{14}$ Next order corrections to the fixed angle predictions (2.4) also occur but have not yet been calculated. The alze of all such non-leading-10g terws decreases for oraller 1 .

(3) The distribution functions $G_{a / A}$ and $G_{b / g}$ are not so easily determined. Even for $a$ and $b$ being quarks the connection between deep Inelastic data and the distribution function is not necesaarlly straight forvard. In particular there are many Indications and comptations ${ }^{\text {is }}$ uhich cuggest that higher trist teras are an important ccoponent of the obherved deep inelastic scale-bresiking. This means that the distribution functions extracted fron the deep Inelastic data could have buch less scale breaklng than wight be nalvely anticlpated when assuning a moderate value of the scale breaking parameter $A$ in (2.3). Substantial higher tulst coniributions lead to a smaller value of $A$ ag excracted froa deep inelastic daca and effect the exact ohape and normalization of the diatribution functions so oblained. Since the higher tulgt contributions decrease with $Q^{2}$ more rapidly than the leading scaleireaking terms an analysis at high $Q^{2}$ would not suffer fram these ambiguities. Unfortunately this requir es large $Q^{2}$ va:ues over a large range in $l o g Q^{2}$. This is not avallable; a recent analygig ${ }^{16}$ whlch employs exiscing neutrino data, with a moojerately high low- $Q^{2}$ cutoff does, in $f a c c$, obtain (with large errors) a lower $A$ value than previous analyses, namely $A=100 \div 100 \mathrm{MeV}$. 
(4) Just as In deep inelastic scattering there may be substantial higher twist contributions to high-p particle froduction. 17 These ariee from hard scactering subprocesses, Inevitably present in $Q \mathrm{CD}$, In which one or more of the participating particles $a, b, c, d$ is non-elementary. A specifle nodel of such higher twit contr1but1ong called the "constituent interchange model" has been proposed 17 because of the earller mentioned success of closely relared diagrans for exclusive reaccions.

An example of the posatble intcrplay between higher twlat and elementacy cCo subprocesges is frovided by $p p \rightarrow \pi X$. There one predicts (In the absence of substantial acale-breaking -- 1.e.. for small $h$ ) on the basis of elementary subprocesses such as qq $+q q$ and hIgher twist CIH subprocesses - such as $\mathrm{qH} \rightarrow \mathrm{qH}(\mathrm{H}=$ meson) (FIg. B)

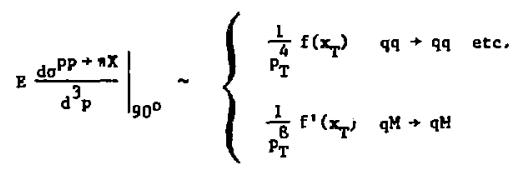

there $x_{T}=2 P_{T} / \sqrt{8}$ and $p_{T}$ is the transverse " woment 1 . The higher tuist $\mathrm{qM} \rightarrow \mathrm{qM}$ coneribution 18 only gignificant because it is enhanced by the oo-called crigger bias effect; ${ }^{18}$ the particular subprocesa $q \mathrm{~K}+\mathrm{q}$ produces the $\pi$ weson directly uhereas it must appesr as a $q$ or 8 frogment for the wore elewentary contributions. The effect Is a suppression of the elementary-QCD

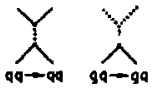

m..."<smiles>CC(C)C1O[As]O1</smiles>

10)

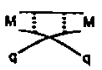

(b) ,..,

F18. 8. Examples of QCD subprocess diagrass for: (a) alementary part1cipants-quarioz and /or gluons; and (b) $\mathrm{qH} \rightarrow \mathrm{qH}$ where $\mathrm{M}=$ meson.

oubproce res relative to the CIM aubprocesses by a factor of 10 compared to their relative Inpurtance in producing jets.

De w11 retura to jets in a mont but let us first look at n eff defined by

$$
\left.z \frac{d_{0} P P+\pi x}{d_{P}^{3}}\right|_{90^{\circ}} \sim \frac{1}{P_{T}^{P_{\text {eff }}}} g\left(x_{T}\right)
$$

as extracted from data. A sraph ${ }^{19}$ obtained fron ISR data 18 shown in Fig. 9. There appear to be tranaltion frow higher neff powers near 8 to lower a power. If one looke at these $\sqrt{3}-53 \mathrm{GeV} / \sqrt{8}-62 \mathrm{GeV}$ extractions this lower power is probsbly between 4 and 5 . Clearly one night be tempted to say that tinere $1 \mathrm{a}$, Indeed, a mixture of CIH and elementary-QCD subprocesses. A superposition of the expressions in (2.6) daes 1ndeed describe this transition. The acenar to is slightly different, however, If $A$ 18 not small but of arder $A=.5 \mathrm{GeV}$. There is chen scale breaking in the quark and gluon distribution functions and non-negligible $a_{g}$ varlation in the elentacary- 
QCD subprocesses. Both effects

tend to Increase $n_{\text {eff }}$ so that In the experimental energy and $x_{T}$ range $n_{\text {eff }}$ should not have fallen below about 5.5 .

In any case, one might be Inclined to belleve that CIK processes are at least responsible for the $n_{\text {eff }} \approx 8$ region at lower $x_{T^{*}}$ This unfortunately, is also oubject to debate. Feynman and Field $d^{20}$ and othera.1 rilaim that one should use on-shell quarkquark scatcering but incorporate the effects of "smear $1 n \mathrm{~B}$ " over the Intrinsic transverse monentum, $k_{T}$, of the quarks 10 the proton. This procedure requires paraneters and cutoffs but probes the $t^{\prime}+0$ singularities of the elementary-QCD $\frac{\mathrm{d} \sigma}{\mathrm{dt}^{\top}}$ 's in ouch a way as to yfold high neff values for these elewentary subprocess contributions at moderate $P_{T^{*}}$ In a Feynman diagram sense, however, the Inttial quarks or gluons entering the subprocess are necessary off-shell. This off-shellness would shield 22 the above $t^{\prime}+0$ siogularity and make $1 t$ impossible to obtain high neff values from $99+99,98+q 8$, etc.; higher twist contributions would then be required to explain the loser $p_{T}$ region of the daca. Simultaneously triggering on two high-p particles on opposite aldes of the beam axis can be showa ${ }^{3}$ to eliminate any possible $k_{T}$ "amearing" effects. As data becones avallable regarding such symercic rriggerg the question of higher-twist versus smearing as an explanation of moderace $p_{\mathrm{T}}$ data should be resolved. Correlations between the quantum numbers of the tro symetric particle triggers will also serve ${ }^{23}$ to discriminate betueen the possible contributing subprocesses; elementary-QCD subprocesses lead to little correlation while higher twiat-CIH subprocesses give rise to substantial correlattons.

(5) Which of the many alternatives scenarios for $n_{\text {eff }}$ considered above actually hold,, If eny, is not clear. In addition, there are other difficulties. Both elementary-QCD and CIM subproc sses, especially the latter, have difficulty 24 In describing the ratio

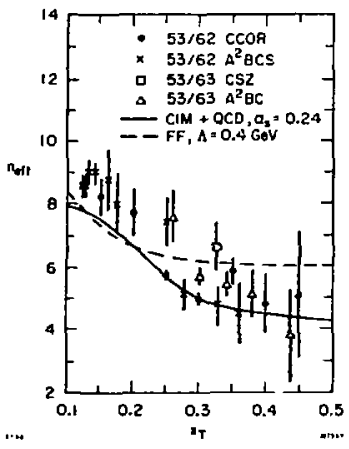

Fig. 9. Effect lve pover $n_{\text {gff }}$ dependence on $x_{T}$ energy $\sqrt{5}=53 \mathrm{GeV} / \sqrt{5}=63 \mathrm{GeV}$ extraction is shown; it probes the highest PT values. Lower energy extractions, e.g., $\sqrt{5}=31 \mathrm{GeV} / \sqrt{6}=53 \mathrm{GeV}$, aluays yield higher neff values since they lover PT values where higher tuist terms are ohown. One uses a superposition of the two terms in (2.6) with no scale breaking. The other is from the Feymman-Field (FF) model with " $k$ gaear Ing" and the QCD scale breakIng paraweter $A=.4 \mathrm{GeV}$.

- 9 - 


$$
\left[E \frac{d \sigma^{\pi-p} p+\pi^{-} X}{d^{3} p}\right] /\left[E \frac{d \sigma^{-p} p \rightarrow \pi^{+} X}{d^{3} p}\right]
$$

as a function of $x_{T}$ and angle. Both predict that the final ${ }^{-}$is more aasily made than the final $\pi^{+}, 1 . e$, , that the quantum numbers of the bear are cransmitced to the finel particle, especially when produced in the forward direction. The data shows 24 alnost no correlation of this type. An addicional problen for the CIM is that the phenomenologically successful noralization of the $Q M+q M$ subprocess, obtained from exclusive $\mathrm{rP}+\pi \mathrm{p}$ and $\pi \mathrm{p}+\pi \mathrm{p}$ scattering data, $17 \mathrm{is}$ much larger than that obtalned in a recent calculation ${ }^{25}$ using the Brodsky-Lepage techniques, 11 Balancing this 1 s the long standing problem fc: elementary-QCD subprocesses of their fallure to predict the observed behavior

$$
E \frac{d \sigma^{P p} \rightarrow p X}{d^{3} p} \sim \frac{1}{P_{T}^{12}} E\left(x_{T}\right)
$$

Which is a natural result ${ }^{17}$ in the CIH due to the existence of the subprocess $q \mathrm{qP} q \mathrm{qP}$ with fixed angle $1 / 8^{6}$ behavio: (uhtch translates into the $1 / \mathrm{P}_{\mathrm{T}}^{12}$ of Eq. (2.9)). The beiravior (2.9) Buggests that the phenomenologically determined CIM subprocess .orzalizatlons are not unreasonable.

(6) As if all the above did not provide sufficlent reason for falling to draw firn conclusions from extsting high- $p_{T}$ single particle data a recent "Jet" experiment ${ }^{26}$ falls to fets fets. Only the elenentary-COCD subprocesses should contribute significsntly to jet cross sections. (The CIM Bubprocesses are no longer enhanced by the trigger b1cs ef fect which results then a single high-p particle is triggered on.) Abyoptotically as $\mathrm{p}_{\mathrm{T}}^{\text {jet }} \rightarrow \infty$, one should see planar events with four jets, two at $h i_{B} h-p_{T}$ on opposite sides of the beam axis and two along either beam axis. While the results are prelininary this planar gtructure is not currentl, observed when the experfment triggers on total large cransverse energy $E_{T}$ on one side of the besm. Inatead the total $E_{T} 19$ composed of many low- $P_{T}$ particles in a variety of different azimuthal and rapidity locations. In addition the cross section is more than a factor of 50 above that predicted by the elementary-QCD subprocesses. One guesses that the

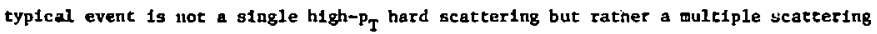
event, each of the multiple collisions being at low- $P_{T^{\prime}}$ Because the trigger is not forcing all the high-P $\mathrm{P}_{T}$ momentun to be carried on a single partiele (as in the single - trigger), the backgrount has becone overwhelming. Or perhaps the theory is orong. At best, far larger valies of $\mathrm{E}_{\mathrm{T}}$ are required before the power-lau-behaved singlehard-scattering cross sections w11l stand out above the background.

Even though hadron-hadron collisions producing a high- $P_{T}$ hadron are st1ll not uamb1guously interpretable, it might be that photon+: adron + hadrun or hadron+ hotron + photon collisions might be beset by fever problews. To some extent this Is the case and it is ac lesgt posstble to learn from these reactions some facts 
Which will be relevant when we come to photon-photon collisfons. Due to lack of space 1 vili discuss only hadron-hadron collisions with production of a single high- $P_{T}$ unaccompained photon. There has been an Increasfins asount of experiaental data ${ }^{27}$ in this scea.

To kiep he discussion simple consifer the two principle competing processes in pp colliatons; an elementary-QCD process $g q+\gamma q$ ylelding $1 / p_{T}^{4}$ beilavior for the Inciusive croas section $E_{\gamma}\left(\mathrm{d} \sigma / \mathrm{d}^{3} \mathrm{P}_{\gamma}\right)$ and a higher twist (CJM) procsss $\mathrm{Mq}_{\mathrm{q}} \rightarrow \mathrm{\gamma q}_{\mathrm{y}} \mathrm{y}$ lelding $1 / \mathrm{p}_{\mathrm{T}}^{6}$ behavior at fjixed $x_{T}$. If we compute the $\gamma / \pi^{0}$ ratio it might be anticipated that some of the scale-breaking and other $\Lambda$ dependent effects wight cancel between the $Y$ and $\pi^{\circ}$ prexictions. Nalvely, ${ }^{2 \theta} 1_{\text {, e., }}$ for small $A$ one obtains $88 p_{T} \rightarrow m, x_{T}=2 p_{T} / \sqrt{s} f \pm x e d$

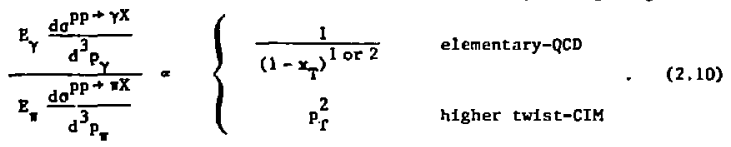

I. elenentery-QCD processes donicate both $Y$ and $\pi^{\circ}$ production the $\gamma / \pi^{\circ}$ racio should be $P_{T}$ independent at fixed $x_{T}$ and a decreasing tunction of $\sqrt{s}$ at fixed $P_{T}$. If higher twist (C1M) diagr ins dominate both reactions the $r / \pi^{\circ}$ raclo should behave as $P_{T}^{2}$

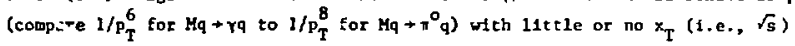
dependepce at fixed $\mathrm{p}_{\mathrm{T}}$. Including other less faportant subprocesse- does not essentially alter the above comparison.

Exporimentally the latest ISR d $\varepsilon t a,{ }^{27}$ which compares $\sqrt{\mathrm{s}}=31,45$ and $63 \mathrm{GeV}$, Indicateg a result wuch nearer the nalve CIM expectation, see FIg. 10. The normalization of the $r / \pi^{\circ}$ ratio 18 coughly a factor of 2 below that originally predicted in Ref. 28, 1.e., within the anticlpated phenomenological normalization uncerzainties. However, to a small extent "scale breaking"29 and to a much larger extent "low $k_{T}$ onearing 30 do pot eatirely cancel out of the $r / \pi^{\circ}$ ratic. In addition Brodsky and $I^{31}$ have conpleted a prelininary computation of the $\mathrm{Mq}+\mathrm{yq}_{\mathrm{q}}$ subprocess normalization In terus of the PCAC constant, $f_{\pi}$, following the cechniques of Ref. 11 and find a resu't consistent with the $\mathrm{qH} \rightarrow \mathrm{qH}$ results of Ref, 25 -- navely a much snaller normalization than obtafned by the earlier phenorenological techniques. 17,28 Thus, the interpretation of hadron-hadron production of high- $P_{T} \gamma^{\prime}$ s even though relatively simpler than production of hadrons at high-p remains untertain at this point in tims. There is gtrong evideace for the point-11ke photon component but the precise subprocess mechaniam by which it enters is not yet clear. Hiere, then,. Jo we turn in order to obtain direct experfmentri verificaclon of the existence of the most elementary QCD reactions, such as

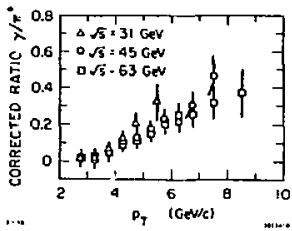

FLg. 10. Comparison of $\sqrt{5}=$ 31,45 and $63 \mathrm{GeV}$ data for $r / r^{\circ}$ at high-pT. Dara is from M. Diakonov et al.. Ref. 27. 
quark-quark scattering, and direct experimental information on the notmalization of higher twit subprocesses? It appears that photon-photon collisions at high- $P_{T}$ provide a much less umbiguous probe of both types of subprocess.

\section{High-P Production In Photon-Photon Reactiong ${ }^{32-36}$}

\section{1. Inclusive Jet and Single Particle Production}

We now turn th a discussion of photon-photon colisions praducing a high- $\mathrm{P}_{\mathrm{T}}$ hadron or jet. Such reactions provide a probe of the same subprocesses as difcusaed In Section II, elementary-QCD and higher twlst-CIM, but will be much less ambiguous Iu their interpretation. For the calculable point-11ke photon conponent: (a) there are many reactions which are predicted to be $A$ Independent in leading order; (b) there are no hadron wave function, smearing, etc. ambiguities; (c) all aubprocess and wave function normailations are explicitly calculable; (d) the contributions coning from the vector-dominated component of the photon can be shown to be small in most situations; and (e) In addition, different types of subprocesses can often be distinguighed through their fingl state topology. We will divide up the high $\mathrm{P}_{\mathrm{T}} \mathrm{2Y}_{\mathrm{Y}}$ oubprocesseg according to Einal otate topology.

\section{A. 2-Jei Processes ${ }^{32-36}$}

In two-photon collisions the simplest gubprocess is that 11lustrated In Fig. 11, $r \gamma \rightarrow q \bar{q}$. The fiasl state is exactly the same as that produced via anothilation (aside from the $\mathrm{e}^{+}$and $\mathrm{e}^{-}$spectators) except that the $q$ and $\bar{q}$ jets do not carry the full energy of the Incomiag $e^{+}$and $e^{-}$. The game cype of diagran can, of course, be drawn for $\mathrm{e}^{+} \mathrm{e}^{-}+\mathrm{e}^{+} \mathrm{e}^{-} \mu^{+} \nu^{-}$. If the Internediate quark propegator in $Y+q \bar{q}$ behaves Just like the elementary nuon propagator in $\mathrm{r}+\mu^{+}{ }^{-}$then the $\mathrm{Yr}^{+}+\mathrm{q} \overline{\mathrm{q}}$ process yields (using the equivalent photon approxination)

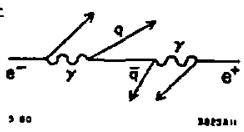

F1g. 11. High-pT q, $\bar{q}$ production via the subprocess $Y Y+q \bar{q}$.

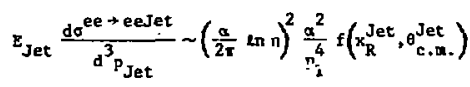

wherc $x_{R}=E_{J e t} / E_{e}$ and

$$
\pi= \begin{cases}\frac{B}{4 \mathrm{~m}_{\mathrm{e}}^{2}} & \text { no electron tas } \\ \frac{\mathrm{G}_{\max }^{2}}{\theta_{\mathrm{m} 1 \mathrm{n}}^{2}} & \text { tagged electron } \\ & -12-\end{cases}
$$


As In annihilation it is conveniert to compare ditectly to the analogous $\mu$-pair crose aection. We obtain

$$
\frac{d g\left(e^{+} e^{-} \rightarrow e^{+} e^{-} g g\right)}{d \sigma\left(e^{+} e^{-} \rightarrow e^{+} e^{-} \mu^{+} \mu^{-}\right)}=R_{r}
$$

wth

$$
{ }_{r}=3 \sum e_{q}^{4}\left(1+O\left(a_{s} / \pi\right)\right)
$$

For atandard fractional charges and two flavor generations $R_{r r}=34 / 27$ in leading order. In a wodel where the photon has a color singlet and a color octet cowonent but experaents are done below color threshold, it 16 still possible ${ }^{37}$ that the octet components of the fnitial phocons could mix together to yield a final state color singlet and yleld a much higher value, nanely $R_{r y}=10 / 3$. In such a model the quark charges are integral abave color threstold.

A ueful characterization of the cagnitude of the two-jet cross section is Its coatrlbution to the standard $R$ value of $\mathrm{e}^{t} \mathrm{e}^{-}$andihilation. Figure 12 fron Ref. 34 shows that the contribution $\Delta R$ (In the fractional charge model) from all $\mathrm{e}^{+} \mathrm{e}^{-}$$e^{+}-\bar{q} \bar{q}$ events with $p_{T}^{\text {quark }}>p_{T}^{\text {min }}$ can be very substantial, especially at lEP energiea,

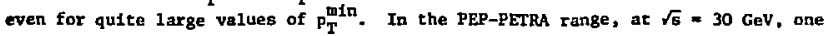
f.tnds

$$
\text { (AR) }{ }_{P_{T}^{\min }}=\frac{5}{\left[p_{T}^{\operatorname{mgn}(C e V / c)]^{2}}\right.}
$$

1.e., wuch prcesses occur at a rate which $1830 z$ of $t$ hat for $\mathrm{e}^{+} \mathrm{e}^{-}+\mathrm{u}^{+} \mathrm{u}^{-}$uhen $p_{T}^{n}=4$ Gev.

A. for the usual anoihilation $R_{3} R_{r}$ bov $O\left(a_{g} / r\right)$ corrections coming frod virtual and real gluon radiation. One anticipates that these w11 be of the aave order as found for $a(-10 z)$. A calculation ${ }^{3 \theta}$ of the $\mathrm{rir}-$ tual part of the corrections appears to canfire this expectation.

The following important polnts should be noted.

(1) Production of cwo jecs (and only two jeta) is algalficant only if the pointlike $y$ component is present. The cross section for two vector esson dowinated photons to collide producing two and only wo jets is cuall. More of ten residues in the beam directions remain as discussed in Section II. A more precise vector-dominance

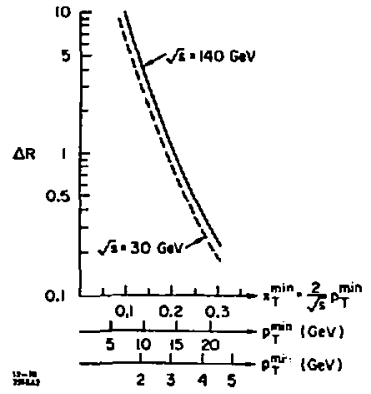

E1g. 12. The contribution to $R$ from $Y Y \rightarrow q \bar{q}$ two-jet processes at $\sqrt{5} \times$ 30 and $140 \mathrm{GeV}$ (from Ref. 34). 
background estimate appeare later, it io bastcally a higher culst concribution uith strong Inverse $P_{T}$ damping.

(2) A fallure to see these purely two-jet everts implies that perturbative Ideas cannot be appiled to short distance physics. This would reptesent a dramatic breakdown of the general approach to short diocance reactions motivated by aymptocic freedon.

In fact, two of the PETRA Broups, PLUTO and TASSO, have aov seen ${ }^{39}$ a feu twojet events with one tagged electron. Such tagging eliatnates a poastbly Ifportant background, discussed in Ref. 34, from annihilation events with wo brenotiahlung photons. Ag the statistics Improve we can clearly expect to either confirm or diaprove the perturbative predictions based on FiB. 11.

There is a second process, $Y Y \rightarrow 88$, Fig. 13, which produces events with exactly two gluon jets. The diagram involves a fermion loop and occurs at order $\left(a_{g} / \pi\right)^{2}$. It might be anticlpated that it would be negligfble; however, explicit calnulatIons 40,4$]$ ahow that

$$
\frac{E\left(d \sigma^{e e}+\text { ee gluon } j e t / d^{3} p\right)}{E\left(d \sigma^{c e}+\text { ce } q \text { or } \overline{j e t} / d^{3} p\right)} \approx .1
$$

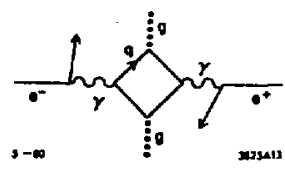

718. 13. Production of two high-P gluon Jeta via $Y \rightarrow B 8$.

earentially Independent of $x_{T}$ and angle. Because of their sintlar angular dependence, kinematics cannot be used to aeparate gluon jets fron quark jets. The only physically ditinguishable features of a glwon jet in this case will be (a) the anticipated higher average multiplicity of gluon jets; $;^{42}$ (b) the brcader tranaverse spread of a sluon fet; ${ }^{43}$ and (c) the polarization of the glwone. 44 with regard to the latter. Ref. 44 shows that even for tmpolarized fnitial photons the gluons are preferably produced wth polarization parallel (I) to the scattering plane as opposed to perpendicular ( $(s)$. They find that

$$
P(\theta) \equiv \frac{d \sigma_{1}-d \sigma_{1}}{d \sigma_{2}+d \sigma_{n}}
$$

becones as large as -0.3 at $\theta_{\text {citon }}^{\text {clio. }}=90^{\circ}$. This polarization 1s, however, only indirectly reflected in an oblaceneas of the gluon jet. 45

\section{B. 3-jet Procesges ${ }^{32-35}$}

This next cacegocy of high $\mathrm{P}_{\mathrm{T}}$ reactions is distinguished by having two high $\mathrm{P}_{\mathrm{T}}$ jeca and one bear direction fet in the final state. Elementary QCD subprocesses which produce such a configuration are shown in F18. 14; they are (a) $\mathrm{rq}+\mathrm{gq}$ and (b) $\mathrm{r} B+\mathrm{q} \overline{\mathrm{q}}$. In two photon collisions these subprocesses yleld one and only one bear jet. The bean jet cones from the rearencs of the photon uhich provides the quark or glvon Iniciating the subprocess. The genertc form of the cross section for production 
of highmp fet is, in the two cases

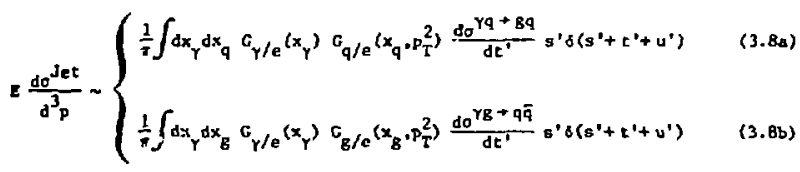

vhere we have used the leading 1 ag result $(2.1)$ and (2.2). The difference between this situation and the hadron target/bean case is that all the above distribution functions are explicirly calculable. The form of $G_{Y / e}$ is obcained 46 from QED

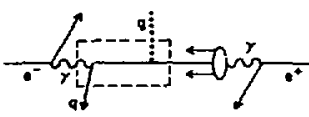

(a)

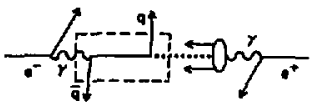

$r-\infty$

(b)

3033418

P18. 14. Elenentary-QCD processes with 3-jet Final state topology. The --- box encloses the high-P subprocess.

Bere the non-trivial $G_{q, g / Y}$ distribution, which will develop a $p_{T}^{2}$ dependence, is comletely calculable, for the point-like photon component. The leading log results

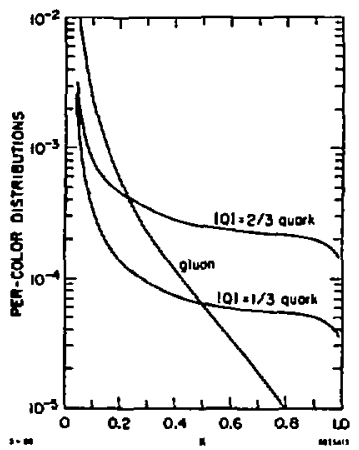
were obtained originally by Wtten ${ }^{47}$ and were rederived diagranatically in Refa. 6, 33 , and 48, wore recently the next order corrections have been obtalned 49 and do not greatly odify the leading log resulte io the eoderate $x$ range. The for of the leading $\log$ regult is shown in F18. 15. (For a wre detalled discussion, see

T. Halsh's talk at this conference or W. Frazer's and W. Bardeen's talkg at the Lake Tohoe Conference. ${ }^{50}$, Both these discributions take the leading $\log$ for

$$
{ }^{G}\left[\begin{array}{l}
q \\
B
\end{array}\right] / \gamma^{\left(x, " Q^{2 n}\right)=\frac{a}{a_{B}\left(" Q^{2} "\right)}}\left[\begin{array}{l}
q(x) \\
g(x)
\end{array}\right]
$$

Fig. 15. Plotced are leading log quark and gluon distributions $G_{q} / \gamma\left(x_{,}, Q^{21 i}\right)$ and $G_{g} / \gamma\left(x_{p} " Q^{2+}\right)$ divided by $\log " Q^{2+1} / A^{2}$.

where " $Q$ " represents the momentum scale of the short distance probe; In our case " $Q 2$ " 
1s of order $P_{T}^{2}$. (Written In terms of $1 / \alpha_{R}$. this form also Incorporates in $2 n$ " $Q$ "') in " $Q$ " corrections to $a_{B}$ ) The important feature is the factortzation of the " $Q^{2}$ " and $x$ dependences; both Increase as $10 g$ " $Q 21 / h^{2}$. In addition $g(x)$ and especially $q(x)$ have much weaker fall off as $x+1$ than comparable distributions for the vectordoninated component of the photon (Bce Ref. 6, for example). Thus the $h 18 h-p_{T}$ gituation (1n which " $Q$ " is of order $P_{T}^{2}$ and $x$ 18 of order $x_{T}$ ) is doninated by the polnt-like component of the photon distribution functions.

The subprocess cross sections for $\mathrm{Yq}+\mathrm{gq}$ and $\mathrm{rB}+\mathrm{q} \overline{\mathrm{q}}$ are, of course, 150 explicitly calculable. ${ }^{32,34}$ both take the form

$$
\left.\frac{d \sigma}{d t^{\top}}\right|_{\substack{\text { fixed } \\ \text { angle }}}=\frac{a_{\theta}\left(p_{T}^{2}\right)}{p_{T}^{4}} f\left(\theta_{c .1 .}^{\prime}\right)
$$

Where $\theta^{\prime}$ c.n. Ho the center-of-mass scatcering angle of the f1pal quark or gluon jet (In the $Y q$ or $r 8 \mathrm{c.m}$. frame) and $P_{T} 1 t s$ transverse momentum; $f\left(\theta_{c . n .}^{\prime}\right)$ is, of course, different for the two reactions. Combining $E q \theta .(3.8)-(3.11)$ ve see that $\alpha_{B}\left(p_{T}^{2}\right)$ cancele between do/dt' and $G_{[q]}$ and that the jet cross section to completely secle Invariant in leading log:

$$
E \frac{d \sigma^{\mathrm{Jet}}}{d^{3} \mathrm{p}} \sim \frac{1}{\left(p_{T}^{\mathrm{Jet}}\right)^{4}} \mathrm{~F}\left(x_{R}^{\mathrm{Jet}}, \theta_{\mathrm{c.t} \cdot}^{\mathrm{Jet}}\right)
$$

where $x_{R}^{J e t}=E_{J e t} / E_{e}$ and $\theta_{c .1}^{J e t}$, is che overall center-of-mass jet scattertag angle. The function $F$ is coapletely determined by the convolution Integrals in Eq. (3.8). The $r q 8 q$ contribution is generally larger than the $r \rightarrow q \bar{q}$ costribution becauge $g(x)<q(x)$ (Fig. 15) over wuch of the $x$ range.

In $\mathrm{Flg}_{\mathrm{g}}$. 16 ve compare, at $\mathrm{e}_{\mathrm{c.z}}^{\mathrm{Jet}}=90^{\circ}$, the cross section $\mathrm{E}\left(\mathrm{do}^{\mathrm{Jet}} / \mathrm{d}^{3} \mathrm{p}\right.$ ) for $\mathrm{Jet}$ production due to the $3-j e t$ processes, $r q+8 q$ and $r \bar{q} \rightarrow 8 \bar{q}$, to that coning from the $\mathrm{r} \rightarrow \mathrm{q} \overline{\mathrm{q}}$ and $\mathrm{rr} \rightarrow \mathrm{gg}$ 2-jet procedses. As expected do(3-jet)<do(2-jec), Clearly, In order to wee a abprocess 1 kke $\gamma q \rightarrow 8 q$ over the $\gamma \gamma+4 \bar{q}$ sut; rocess, $1 t$ ir neceseary to dietinguieh the 3-jet from the 2-jet topology.

The fact that there are only two 3-jet proceses at the elenentary-QCD level ankes it posalble to also Inagine tenting the abociated predictions 51 for energy distribution in the beal jet and for angular diseributions of the opposite side jet relative to the trigger jet. But the moac crucial observation is that in leading $10 g$ none of the $A$ dependent complexties assoctaced with hadron targeta arise. These elementary-QCD subprocebes y1eld $a_{5}$, and hence $A$, Independent answer in leading order. 52 Next-to-leading log corrections need to be computed for these jet cross eectiona but are prabably no larger than those found in hadron target scatcering. 


\section{c. 4-Jec Processess $32-35$}

Examples of subprocesses which contribute to the 4-jet topology ( 2 balancing high- $\mathrm{P}_{\mathrm{T}}$ Jets and 2 beam direction jets) at the elementary QCD level are shom in Fis. 17. Of course, many diagrams and processes are not showr. Note that since the point-11ke-photon quark distribution, $q(x)$, is so much larger (F1g. 15) than the gluon distribucion, $g(x)$, the subprocesseg $\mathbf{q q} \rightarrow \mathbf{q q}, \mathbf{q \overline { q }} \rightarrow \mathbf{q \overline { q }}$ and $\overline{\mathbf{q q}}+\overline{\mathbf{q q}}$ dominate.

The generic form of the cross section fron the $4 q^{\circ} \rightarrow q q^{\prime}$ aubprocess is

$$
\begin{aligned}
& E \frac{d \sigma^{J e t}}{d^{3} p} \sim \frac{1}{\pi} \int d x_{q} d x_{q}, G_{q / e}\left(x_{q}, P_{T}^{2}\right) \\
& \times G_{q^{\prime} / e}\left(x_{q^{\prime}}, P_{T}^{2}\right) \frac{d d^{q q^{\prime}+q q^{\prime}}}{d t^{\prime}} \theta^{\prime} \delta\left(s^{\prime}+t^{\prime}+u^{\prime \prime} ;\right.
\end{aligned}
$$

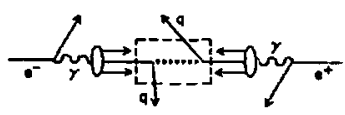

(o)

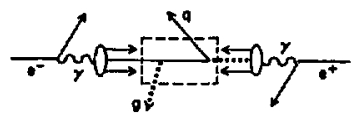

(b)

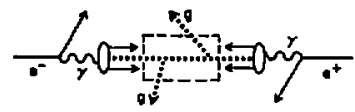

$1-\mathbf{n}$

(c)

F18. 17. Examples of elementaryQCD subprocesses contribueing to the 4-jet topology: (a) $99+99$; (b) $98+98$; and (c) $88+88$. The order ts one of decressing 1aportance as the gluon distribution for the point-like photon is generally smaller than the quark distribution.

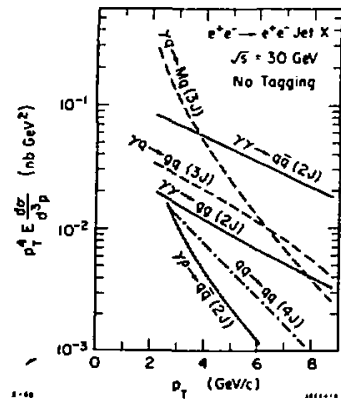

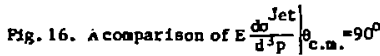
coning fron various 2-Jet ( $\longrightarrow$, 3-Jet (-), and 4-jet (-.-) processea. Except for the $Y P+q \bar{q}$ curve all subprocess contributions are calculated using the point-IIke photon component only; in particular inttial quark are obtained from the $P$ ? dependent point-like photon distribution. In the curves labeled $\mathrm{rq} \rightarrow \mathrm{Hq}$, $\mathrm{rq}+\mathrm{Bq}$ and $\mathrm{qq}+\mathrm{qq}$ we have al so $\mathrm{in}-$ cluded the antiquark contributions $\gamma \bar{q} \rightarrow M \bar{q}, \gamma \bar{q}+8 \bar{q}$ and $q \bar{q}+q \bar{q} / \bar{q} \bar{q}+\overline{q q}$, respectively. with $G_{q / e^{G}} q^{1 / e}=\left[1 / a_{s}\left(p_{T}^{2}\right)\right]^{2}$, nee Eq. $(3.10)$, and, frorr (2.2),

$$
\frac{d q^{q q^{\prime} \rightarrow} q q^{\prime}}{d t^{\prime}} \sim \frac{1}{p_{T}^{4}} a_{g}^{2}\left(p_{T}^{2}\right) f^{q q^{\prime}+q q^{\prime}}\left(\theta_{c .=.^{\prime}}^{\prime}\right) .
$$

Thus the $a_{6}\left(P_{I}^{2}\right)^{\prime} s$ cancel and one obtains

$$
\left(E \frac{d o^{J e t}}{d^{3} p}\right)_{q q^{\prime}+q q^{\prime}} \sim \frac{1}{P_{T}^{4}} E^{q q^{\prime}+q q^{\prime}}\left(x_{R}^{J e t}, \theta_{c . n .}^{J e t}\right)
$$

As in the 3-jet case $F^{q q^{\prime}+q q^{\prime}}$ is conpletely 
calculable and scale invariant; In leading order the A dependence and other abobiguties which plague the hadron target case are absent. of course, all the other elewentary-QCD subprocesses combine vith their appropriate quark/gluon distribution functions in the convolution integral so that this sane $a_{a}\left(p_{T}^{2}\right)$ cancellation occurs. The $(q q+q q)+(q \bar{q}+q \bar{q})+(\overline{q q} \rightarrow \overline{q q})$ subprocess contribucion to $E\left(d \sigma^{-J e t} / d^{3} p\right)$ is show in Fig. 16. Agaln we have the natural ordering do(4-jet) < do(3-jet) < do(2-jet). Note, however, that this is not an ordering in $a_{g}$ (the $a_{a}^{\prime a}$ always cancel). Recher the otdering reflects the "directaess" with which the final fet is produced; those subprocesces which "waste" energy in the bean direction are suppregsed relative to those with less beam direction loss,

Another global picture 1s provided by Fig. 18 from Ref. 34. There we plot

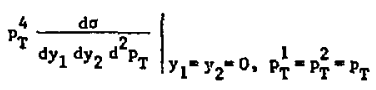

wher ve inagine triggering on two jets, back-to-back at $.90^{\circ}$ with equal $P_{T}{ }^{\prime} \theta$. This plot incorporates all ubprocesseg of the elementary-qCD type which contribute to the various jet topologies.

D. H1gher Ivist and Vecror-Dominance Ef fects -Single Particle Spectra

(a) Higher Tulst and Single Particle Spectra

At chlo point the alert reader might ask if there are not sose higher tulat diagrans which complicate the high-p fet situation. The answer, fortunately. IE In general "uo." Only one such diagram lo 11kely to be Irportant. It contributes to the 3-jet case and $1 \mathrm{~s}$ based on the subprocess $\mathrm{rq}+\mathrm{Mq}$ (the reveraal of wich was discussed in Section II). The centerof-aiss diegran, FIB. 19, is exactly analogous to thet drawn for $\mathrm{rq}+\mathrm{gq}, \mathrm{P} 1 \mathrm{~g}$. 14, but with the gluon replaced by a meson. As discussed in Section II, the $r q \rightarrow M q$ subprocess yields $I / P_{T}^{6}$ behavior compared

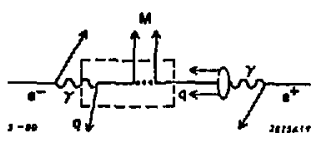

F1g. 19. Higher nust 3-jet copology diagram based on the subprocess $\mathrm{rq}+\mathrm{Kq}$.

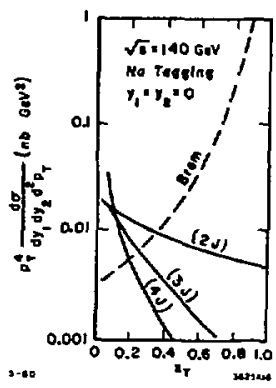

F1B. 18. LEP energy plot of the complete double jet trigger cross sectior. coming from elementary-QCD;\% ; ocesaes of each topology type. Al shown is the double bremsstrahlung background which can be eliminated by single tagging, see Ref, 34. to $1 / \mathrm{P}_{\mathrm{T}}^{4}$ behavior for the $\gamma q \rightarrow \mathrm{BQ}$ subpracess:

$$
\frac{d \sigma^{T q \rightarrow H q}}{d t^{\top}} \sim \frac{a_{s}^{2}\left(p_{T}^{2}\right)}{p_{T}^{6}} \hat{\mathbf{f}}\left(\theta_{c=\text { II. }}^{\prime}\right)
$$

with $\hat{f}$ completely calculable aside from its

$$
-18=
$$


normalization. Either the final meson or final quark can yleld an observed "Jet;" If the "Jet" derives fros the meson it will have limited multiplicity and should reconstruct to a resonance. The form of the cross section is

$$
\begin{aligned}
E \frac{d \sigma^{J e t}}{d^{3}} & -\frac{1}{\pi} \int d x_{Y} d x_{q} G_{Y / e}\left(x_{Y}\right) G_{q / e}\left(x_{q}, P_{T}^{2}\right) \frac{d g^{Y q}+1 k q}{d \tau^{\prime}} s^{\prime} \sigma\left(s^{\prime}+\tau^{\prime}+u^{\prime}\right) \\
& \sim \frac{1}{P_{T}^{6}} a_{s}\left(p_{T}^{2}\right) \hat{F}\left(x_{R}^{J e t}, \theta_{c . d .}^{J e t}\right)
\end{aligned}
$$

The furction $\hat{\mathrm{F}}$ is completely determined by the above convolution integral and $\overrightarrow{\mathbf{f}}$ of Eq. (3.16). Thus only its normalization is uncertain. This nomalization is of great theoretical interest.

The normalization of $\hat{\mathrm{f}}\left(\theta_{\mathrm{c} . \omega .}^{*}\right), 1 . e$, of $\mathrm{rq}+\mathrm{Hq}$, has been determined phenomeno$\log 1 \mathrm{ca} 11 \mathrm{y}^{17,32}$ in a vartety of different ways. The cruclal Ingredient is the notmalizacion of the meson wave function. This has been obtained from:

(a) Ip - Tp elastic scatrering which in the CD is normalized by the proton form fector and the $r$ wave function.

(b) Hq $\rightarrow \pi q$ exclusfve scattering, the normallzation of which is determined by the size of the C1M contribution to $\mathrm{PP} \rightarrow \mathrm{IX}$ at high- $\mathrm{P}_{\mathrm{T}}$.

(c) $\mathrm{MA}+Y \mathrm{Y}$, the nomalization of which is deternined by the size of the CMM contribution to $\mathrm{pP}-\mathrm{rX}$.

All three deteralnations are conpletely consistent with one another. For Instance If $\mathrm{p} \mathrm{-} \mathrm{ip} \mathrm{elastic} \mathrm{scattering} \mathrm{is} \mathrm{used} \mathrm{to} \mathrm{deterwine} \mathrm{the} \mathrm{normalization} \mathrm{of} \mathrm{the} \mathrm{meson}$ wave function, then the higher $\mathrm{W}$ ist $\mathrm{CD}$ diagrams baaed on the subprocessea $\mathrm{Hq}+\pi \mathrm{q}$ and $\mathrm{Hq} \rightarrow \mathrm{rq}$ yleld excellent fits to $\mathrm{PP} \rightarrow \pi \mathrm{X}$ and $\mathrm{pP} \rightarrow \mathrm{\gamma X}$ high-p $\mathrm{T}$ data, recpectively. It 18 also possible co calculate the meson vave function inrmalization using the techniques of Ref. 11.31 A much smaller normalization is obtalned; but it is difflcult to 1gnore the phenomenological successes $(a)-(c)$. Thus a clean deteraination of the normalization of $\hat{f}\left(\theta_{c . m .}^{\prime}\right)$ is highly destrable.

In FIg. 16 we compare the CIM 3-jet process contribution to jet production at $\theta_{c . w .}^{\text {Jet }}=90^{\circ}$ to those prevlously discussed -- using the normalization of (a)-(c) above. Only at lower $P_{I}$ values does the CII process clearly dominate the 3-jet topology contribution to jet production.

Bowever, as mentionat in Section II, 1 ve trigger on a single fasc meson, e.g., . . + , ther the $\mathrm{Yq}^{+}+_{\mathrm{q}}^{+}$subprocess can produce the $\hbar^{+}$directly whereas the $\mathrm{rq}+\mathrm{gq}$ and $\mathrm{rg}+\mathrm{q} \overline{\mathrm{q}}$ subprocesses as well as the nuch more Important $r \mathrm{r}+\mathrm{q} \bar{q}$ subprocess must create the $i^{-4}$ as f fragaent of a quark or gluon. The jet cross section fron the $\mathrm{Yq}+\mathrm{Kq}$ subprocess 16 roughly a factor of 20 above the direct ${ }^{+}$cross aection (a factor $10 \mathrm{fe}$ due to the restriction to $\mathrm{M}=\mathrm{n}^{+}$conpared to arbitrary $\mathrm{M}$ and - factor of 2 from loss of the q jet triggering pussibility). In comparison $r \gamma \rightarrow q \bar{q}$ with $q$ or $\bar{q}$ fragmenting to the $\pi^{+} 16$ suppressed by roughly a factor of 100 relative 
to itg jet cross section, mostly becsuse of the trigger bias effect.18 Thus there Is a relative enhancepent of the CIM subprocess ty a factor of 5 in the single t $^{+}$ trigger gituation. The three post inportant single pion spectrum contributions are given in $\mathrm{F} 1 \mathrm{~g}$. 20 (at $\theta_{\mathrm{c}}^{\mathrm{F}^{+}}=90^{\circ}$ ) whete $1 \mathrm{t}$ is oeen that the $\mathrm{CIM}$ ters doninates over the $p_{T}$ range chown, if the normalization from (a)-(c) 16 employed.

Prellaliary "aingle tag" spectra for $\left(d N^{e e} \rightarrow e e \pi X / d p_{T}^{2}\right.$ ) have been obtalned by both TASSO and PLUTO. ${ }^{39}$ Both exhibit a sharp break at $p_{T}^{2} \approx 1(\mathrm{GeV} / \mathrm{c})^{2}$ and a large high$P_{T}$ ta1l. A detalled study of these spectro should clearly deternine whether or not there is room for a large CIM contribution; triggering efficiencie日, etc., must be unfolded before comparison to theory cas be sade.

\section{(b) Vector Dominance Backgrounis:}

. In Figs. 16 and 20 we have also plotted the largest vector dominance backgrounds, to jet and single $n^{+}$production respectively. In the jet case we have compared the 2-jet contribution cowing frow the subprocess $\mathrm{ro} \rightarrow \mathrm{qq}$ (1.e., one of the Initial two photons ls vector dowinated as shown in F1g. 2la) to the purely point-11ke d1agran baged on $r+q \bar{q}$. The process $\gamma p+q \bar{q} 1 \mathrm{~g}$ a higher-tolst relative of $r \rightarrow q \bar{q}$ ylelding $1 / \mathrm{p}_{\mathrm{T}}^{6}$ va. $1 / \mathrm{p}_{\mathrm{T}}^{4}$ behavior for the jet cross section. Nor surprisingly it is very uuch euppressed. This is cypical of veccor dorinance backgrounds. For a given topology

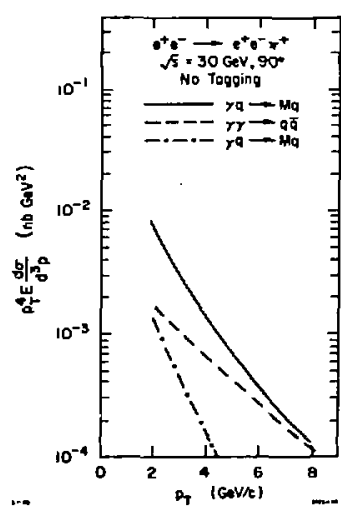

F1B. 20. Contributions to ${ }^{+}$producrion at $90^{\circ}$ from: (a) $\mathrm{YQ}+\mathrm{x}_{\mathrm{q}}^{+}$where the $q$ cowes from the point-like photon component; (b) $\mathrm{rr} \rightarrow \mathrm{q} \bar{q}$ with either the $q$ or $\vec{q}$ fragmenting to the observed $\pi^{+}$; (c) $r q \rightarrow \pi+q$ where the initial q comes from the vector-doninated photon component.

(2, 3 or $4 \mathrm{jet}$ ) the vector doninance related backgrounda are suppressed relative to the analogous point-11ke photon contributions by at least a factor of 10 .

Another example in the $j$ et case (not plotted in Fig. 16) is the comparison of 4-jet contributions fron the $q q+q q$ scattexing subprocess. If the iaftial quarks

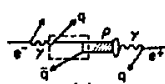

(a)

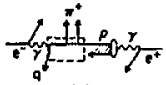

(b) sustin

F1g. 21. Vector dominance backgrounde to (a) 2-jet product 1on; (b) $\mathrm{A}^{+}$productson.

are both from p-dominated photons the contribution 18 a faptor of $10^{3}$ below the contribution where both of the Initial quarks come from the point-11ke photon components, as In E1g. 17a. This reflects the dominance of polnt-11ke vector-dominated components of the quark diseribution in a phocon. Thus 
even If the po + 4-jet cross sectfon $t s$ an unexpectedly small perrentage of the calorimetric trigger rate, as appeats to be the cage in hadron-hadron collisicis (aee Itew (6) under Section II), It way still be that the simple point-1ike process $\mathrm{Y}_{\mathrm{FL}} \mathrm{Y}_{\mathrm{PL}} \rightarrow$ 4-jet w11 atand above the hadron-related background.

Out final vector dorinance example is the contribution to single $\pi^{+}$production coming Erow the subprocess $\gamma q \rightarrow \pi^{+} q$ with the initial quark coming from a $p$-dominated photon, F1g. 21b. Figuce 20 showg that this background is suppressed by a factor of 2 I relative to the analogous contribution coming from $\gamma q+\pi^{+} q$ wth the inftial quack frou a point-like photon diatribution.

To sumarize Section III.l on Inclustve high- $\mathrm{P}_{\mathrm{T}}$ reactions in $\mathrm{rr}$ collisions we firat reemphaoize thet high-P phyatca is relatively clean in this aituation compared to typical hadronic collisions. Possible problems are confined co:

- Hon-1eading-log corrections -. posalbly as small as lot fót the 2-fet topology and probebly about $5 c z$ for 3 and 4-jet topoiogies.

- Iocorporating the non-zero $\left\langle q^{2}\right\rangle$ of photons coming from an $e^{-}$or $e^{+}$that 10 triggered on.

* Thresholds - In leading log tinese effects enter through the aumer of photon quark components we consider. As $p_{T}^{2}$ increeses one, for instance, passes new 2-jet $\gamma+q \bar{q}$ thresholds when $w_{\text {subprocess }}^{\frac{T}{2}} * 4 p_{T}^{2} \geq 4 m_{q}^{2}$. Effects of aes querk thresholds which enter through $a_{s}$ tend to cancel aince $a_{s}$ "s zancel in wost cases.

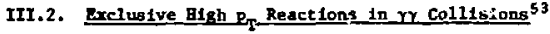

Two photon collistuns provide testa of QCD which are analogous in simplicity to, but wore versatile than, those provided by form fuctor mesureaents. I w11 discuse briefly only tro examples:

(a) $r^{*}\left(Q^{2}\right) r+r^{\circ}$

If we define the Invariant Feynen arplitude as

$$
H=1 e^{2} r_{T \gamma}\left(Q^{2}\right) c_{\mu v p \sigma} P_{\pi}^{v} q^{p} c^{\sigma} \quad,
$$

then the exact prediction to equivalest to exposing one gluon in the $7^{\circ}$ vave function a6 in F18. 22,

$$
F_{\mathrm{TY}}\left(Q^{2}\right) Q^{2} \pm-\frac{2 f}{Q^{2}}
$$

wth no a, or $A$ dependence In this leading order. (The PCAC constant as defined here I. $f_{x}=0.093 \mathrm{GeV}$ ) This to the same prediction as obtained many years earlier using PCAC and the Bjorken, Johnson, Lov

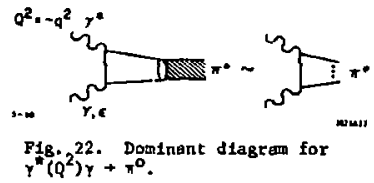


11nit. 1 It is a fundamental and siople test of the perturbative approach to short distance physics.

(b) $\boldsymbol{m}+\mathbf{m} \overline{\mathbf{H}}$

Here we consider oaly real photans. The "Borm" diagrams which contribute in the large $Q^{2}$ fixed angle liate are shom ia Fig. 23 . After including all leading 108 corrections the prediction takes the form

$$
\begin{aligned}
H_{\mathrm{V}+M \bar{M}} & =\frac{e^{2} 16 \pi a_{B}\left(Q^{2}\right)}{3}\left[\varepsilon_{1} \cdot \varepsilon_{2} H_{1}\left(z, \log Q^{2} / A^{2}\right)\right. \\
& \left.+\frac{4 \varepsilon_{1} \cdot k \varepsilon_{2} \cdot k}{Q^{2}} \mathscr{H}_{2}\left(z, \log Q^{2} / \Lambda^{2}\right)\right]
\end{aligned}
$$

where $z=\cos \theta, n$, of the final $M$ and

$$
\mu_{1}=\sum_{n=0} b_{n_{0}, a^{1}}^{1}(2)\left(\log Q^{2} / \Lambda^{2}\right)^{-\gamma_{n}-\gamma_{m}}
$$

The $r_{n}$ and $r_{n}$ are the anomalous dimensions which appear in deep Inelestic scattering and the form factor prediction, Eq. (2.5), and the leading terms $b_{00}^{1}(x)$ are calculable in terms of the PCAC $f_{\pi}$. Hote that the

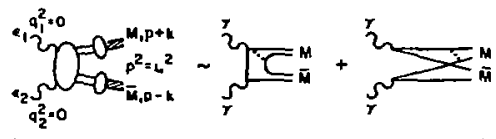
$b_{n, 1}^{1}=180$ depend ca scattering

Fig. 23. Diagrams for $r y+M \bar{M}$. angle $z$ so that the $z$ dependence of the cross section can in principle be ured to separate the different b's from one another.

Again the above are fundamental yet afmple predictions of QCD. These exclusive reaction may be afmler to andyze (despite tbeir relatively small cross aection) than the inclustve reactions. However, only in the fnclusive reactions to it pouable to directly probe the simple QCD processes qq $\rightarrow q q, r \rightarrow q \bar{q}$, etc. Clearly both types of experlment deserve long-term attention and analyals.

\section{Iv. Conclusions}

We sumarize the nalp points of this talk.

(a) The precise low energy ory forn needs more theoretical attention. It 15 abundantly clear that eatiuates of the non-Pomeron contributions to ory using vector doalnance will yield only pact of the answer. Additional Regge and/or Elxed pole contributions, Ielated to the polnt-like component of the photons, will be present. 
(b) He are fortunate in the high- $\mathrm{p}_{\mathrm{T}}$ domain to have a potnt-1ike photon component. Already experiments have seen the fundamental 2-jet signal predicted on the basis of the perturbarive process $Y Y+q \bar{q}$. In cowpartson hadronic collistons present a confusing p'cture, even refusing (according to a recent experiment) to yieid a clear jet trigger signal whout first biesing the event by requiring a single fast high-p particle.

(c) Kost two-photon high-p $\mathrm{P}_{\mathrm{T}}$ predictions exhibit exact scaling and are Independent of the QCD A paraneter in leading order. All normalizations are computable. The tests of the underlying elementary-QCD cross sections are correspondingly clean.

(d) Higher tuist and vector dominance related backgrounds are generally negligtble except for the interesting $\gamma \gamma+\pi^{+} x h i g h-p_{T}$ single particle cross section which provides a simple and fundemental measure of the normalization of an imporcant hibher-twist subprocess, $Y q \rightarrow \pi q$. Experimental results on $d N^{Y Y+\pi} / d p_{T}^{2}$ will shorcly provide meaningful constraints.

(e) Fundamental, but sImple, QCD predictions have been obtained for several bastc exclustve channels in photon-photon collistons.

\section{Acknowledgetaents}

I vould like to thank P. Kessler and G. Parisi for their hospitality at the Anlens Two-Photon Workshop (1980) for which this talk was prepared. I would also like to thenk S. J. Brodaky for communicating hig recent exclusive results to me.

\section{References}

L. See M. Greco's talk at the "Workshop on Two Photon Collisions," Antens, France (1980) and references therein.

2. F. E. Low, Phys. Rev. D12 (1975) 163; S. Nuss1nov, Phys. Rev. Lett. 34 (1975) 1286; J. F. Gunion and D. B. Soper, Phys. Rev. D15 (1977) 2617.

3. See the talks of Ch. Berger (PLUTO) and E. HUlger (TASSO) at the "Workshop on Two Ehoton Collistons," Amiens, France (1980).

4. J. F. Gunion, Phys. Lett. 88B (1979) 150.

5. V. Chang and R. Hwa, Phys. Lett. 85B (1979) 285.

6. See for example, W. R. Frazer and J. F. Gunion, Phys. Rev. D20 (1979) 147.

7. The actual prediction incorporating spin $1 s(1-x)^{2}+$ constanc, $(1-x)$ is an adequate approximation over the moderate $x$ domaln. See $C$. Farrar and D. R. Jackson, Phys. Rev. Lett. 35 (1975) 1416.

B. The actual prediction is $\frac{(1-x)^{0}}{a+b \ln (1 / 1-x)}$ indicating a logarithric suppression an $x+1$, See Ref. 6 .

9 A. M. Boyarsk1 et al. Phys. Rev. D14 (1976) 1733. Th1s is $18 \mathrm{GeV} \mathrm{YP} \rightarrow \pi^{+}, \pi^{-}$ data. H1gher energy data from the tagged photon bean at FNAL will hopefully confirn this lower energy result. 
10. See for example, W. Frazer and J. F. Gmolon, Phys. Rev. D19 (1978) 2447 and references therefn.

11. Por s gumary of recent progress in this area see S. J. Brodal:y, SLAC-PUB-2447, presented at the Sumer Intitute on Particle Physics, SLAC (1979).

12. R. BIankenbecler, S. J. Brodsky and J. F. Gunlon, Phys. Rev. DA (1973) 4117; Phys. Lett. 39B (1972) 649; R. V. Landshoff and J. C. Polk1nghorne, Phys. Rev, D10 (1974) 891 and refezences therein; H. K. Chase and H. J. Stirling. Nucl. Phys. B133 (1978) 157. For a general revlew gee D. Sivers, R. Blankenbecler and S, J. Brodeky, Phys, Rep. 23C (1976) 1 and Ref. 11.

13. See Ref. 11 and r.. P. Lepage and S. J. Brodgky, Phys. Rev. Lett. 87B (1979) 359.

14. R. K. Ell1s, M. Furman, B. Haber and T. Binchliffe, LBL-103C4 (1979).

15. See L. F. Abbott and R. M. Barnett, SLAC-FUB-2227, submitted to AnnalE of Phys.; R. Blankenbecler and I. Schmidt, Phys. Rev. DL6 (1979) 1318; W. R. Frazer and I. Schmidt, Phys. Rev. D16 (1979) 1318; W. R. Frazer and J. F. Gunlon, SLACPUB-2489 (1980). The general form of higher twlst contributions uas first discussed In R. Blankenber . I, S. J. Brodsky and J. F. Gunton; Phys. Rev. D12 (1975) 3469.

16. R. M. Bamett, private comunication.

17. See R. Blankenbecler, S, J, Brodaky and J. F. Gumlon, Phys. Rev. D18 (1978) 900; D. Jones und J. F. Gunion, Phys, Rev. D20 (1979) 232.

18. S. D. E1118, P. V. Landshofe and H. Jacob, Nucl. Phys. B108 (1978) 93.

19. Experimental polnts are frow R. Stronowsk1, StaC Sumer Institute on Particle Physics (1979). Experimental references can be obtained there. Tbe $\sqrt{6}=31 /$ $\sqrt{A}-53$ neff extractions are reaved from Stronowsk's graph. A differenc range of $\mathrm{PT}_{\mathrm{T}}$ is being probed compared to the $\sqrt{\mathrm{B}}=53 / \sqrt{\mathrm{B}}=62$ excractiong (at $x_{T}=.4, P_{T}=6$ to $10 \mathrm{vs} . \mathrm{P}_{\mathrm{T}}=10 \mathrm{ko} 12$ ). More higher tuist-CDM couponent $1 \mathrm{~s}$ expected (and seen) in the fower $\sqrt{s}$ extraction; correcting for this yields apploximate agreement betuees the two extractions. I have alsn added to Stronorsk1's graph receat $a_{e f f}$ val tes obtalned by the Athene, Achens, Broakhaven, CERY collaboration $\left(A^{2} B C\right)$, C. Rourxolmel1s et el. , CERH-ET/80-07.

20. See R. P. Feyman, R. D. Field and G. C. Fox, Nucl. Phys. B128 (1979) ; Phys. Rev, D18 (1978) 3320 , A var1ety of others have also pursued such studies. For rezerences see Refs, 11 and 19. See also R. Fleld, Proceedings of the Tokyo International Conference on High Energy Physics (1978).

21. See Ref. 19 for a discussion and further references.

22. W. E. Caswe11, R. Horgan and S. J. Brodsky, Phys. Rev. D18 (1978) 2415; R. Borgan and P. Scharbach, Phys. Lett. 81B (1979) 215.

23. J. P. Guntion and B. Peterson, O.C. Davis preprint UCD-79-5, Phys. Rev. to be published. Elementary QCD processes were considered in more detall by R. Baier, J. Cleyanang and B. Petersson, Phys. Rev. D17 (1978) 2310.

24. B. Frtoch et al., Phys. Rev, Lett. 44 (1980) 511.

25. G. R. Farrac and G. C. Fox, Rutgere preprint, RU-79-170 (1980).

26. See $P$. Seyboth'e contribution at the Rencontre de Yorlond, Les Arca, Prance (1980).

27. R. H. Baltrugatt is et al., FNAL-PUA-79/38 Exp (1979); E. Anald1 et al., Nucl. Phya. B150 (1979) 326; M. Diakonov et al., CERh-EP/80-02 and 80-03.

28. R. Ruckl, S. J. Brodsky and J. F. Gunlon, Phys. Rev. D18 (I978) 2469.

29. A. P. Cantogouris, S. Papadopoulos and M. Bongoh, Phys, Rev. Di6 (1979) 2607.

30. L. Cocmell and J. F, Owens, FSU-HEP-800307 (1980).

31. S. J. Brodsky and J. P. Gunton, in progress. 
32. S. J. Brodsky, T. DeGrand, J. F. Gunlon and J. Hels, Phys. Rev. Lett. 41 (1978) 672; and Phys. Rev. D19 (1979) 1418.

33. c. H. Llewellyn Solth, Phys. Lett, 79B (1978) 83.

34. K. Rajantie, Phys. Scripta 29 (1979) 230; K. Kajant1e and R. Ra1tio, Nucl. Phys. B159 (197) 528.

35. H. Abud, R. Gatto and C. A. Suvoy, Phys. Rev. D20 (19791 2224; and Phys. Lett. $84 B(1979) 229$

36. S. Berman, J. Bjorken and J. Kogut, Phys. Rev. D4 (1971) 3388.

37. See also M. Chanow1tz, Proceedings of the XIIth Rencontre de Moriond (197i), edited by Tran Thanh Van; P. V. Landshoff, LEP Summer Study, 1-13 October 1978; and S. J. Brodsky and J. M. Wets, Menorial Symposium on Strong Interactions (1978), University of Hashington. H. Lipkin, Nucl. Phys. B155 (1979) 104, feels that color fluctuations invalidate this result; however the contribution is basically of a "z-graph" type (refering to time ordered perturbation theory) which would not be affected by color fluctuations. The issue is not yet settled.

38. F. Berends, 2. Kunszt and R. Gastmans, DESY preprint, DESY-80/08 (1980).

39. See the talks by $\mathrm{Ch}$. Berger (PLUTO) and E. Hilger (TASSO) at the Amiens "TwoPhoton horkshop (1980).

40. R. Cahn and J. F. Gunton, Phys. Rev. D20 (1979) 2253.

41. K. Kajantie and R. Rait1o, Phys, Lett. 87B (1979) 133.

42. See for example, S. J, Brodsky and J, F. Gunion, Phys. Rey, Lett. 37 (1976) 402; X, Konish1, A. Ukawa and G. Veneziano, Phys. Lett. 78B (1978) 243.

43. See G. Venezlano, XIXth International Conference on High Energy Phystcs, Tokyo (1978).

44. A. Devoto, J. Pumplin, W. Mepko and G. L. Kane, Michigay State Univergiey preprint (1979).

45. 5. J. Brodsky, T. A. DeGrand and R. E. Schuicters, Phys. Lett. 79B (1978) 244.

46. See the talks by P. Kessler, G. Parisl and J. Fleld at the Ariens "Two-Photon Horkshop" (1980) for a critical revieu of various approximations to $\mathrm{G}_{\mathrm{r}} / \mathrm{e}^{-}$In the results quoted here I always use the equivalent phaton spectrum.

47. E. Witten, Nucl. Phys. B120 (1977) 189.

48. Y. Dokshitser, D. Dyakonov and S. Troyan, SLAC-TRANS-183; R. J. DeWItt, L. Jones, J. Sullivan, D. Nillen and H. Wyld, Phys. Rev. D19 (1979) 2045́.

49. W. Bardeen and A. Buras, Phys. Rev. D20 (1979) 166; D. Duke and J. Dwens, Florida State InIversity, FSU-HEP-802 401 (1980). These latter authors now agree with Bardeen and Buras.

50. T. Halsh, Anfens "Two-Photon Hoxkshop" (19:0); W. Bardeen, Lake Tahoe Tuo-Photon Conference (1979); W. Frazer, Lake Tahoe Two-Photon Conference (1979).

51. J. Ffeld, E. Pfetarinen and K. Kajantie, DESY preprint 79/85 (1979).

52. Actually $(3.10)$ and $(3.11)$ are st11l correct when the Important in $2 n p_{7}^{2} / 2 n p_{T}^{2}$ corrections to $a_{6}(p)$ are included and thus the scale invariance of $(3.12)$ is only corrected by terms down by a full power of $\ln p_{\mathrm{T}}^{2}$.

53. This section $1 s$ based on work due to S. J. Brodsky and G. P. Lepage, Ref. 11 (and references therein) and work in progress. 